\title{
The Physical Internet and Business Model Innovation
}

\section{Benoit Montreuil, Jean-François Rougès, Yan Cimon, and Diane Poulin}

\author{
"Amateurs discuss tactics; professionals discuss logistics. ") \\ Napoléon Bonaparte (1769-1821)
}

\begin{abstract}
Building on the analogy of data packets within the Digital Internet, the Physical Internet is a concept that dramatically transforms how physical objects are designed, manufactured, and distributed. This approach is open, efficient, and sustainable beyond traditional proprietary logistical solutions, which are often plagued by inefficiencies. The Physical Internet redefines supply chain configurations, business models, and value- creation patterns. Firms are bound to be less dependent on operational scale and scope trade-offs because they will be in a position to offer novel hybrid products and services that would otherwise destroy value. Finally, logistical chains become flexible and reconfigurable in real time, thus becoming better in tune with firm strategic choices. This article focuses on the potential impact of the Physical Internet on business model innovation, both from the perspectives of Physical-Internet enabled and enabling business models.
\end{abstract}

\section{Introduction}

The way physical objects are moved, handled, stored, realized, supplied, and used throughout the world is not sustainable economically, environmentally, or socially. Trucks and containers are often half empty at departure and often return empty. Vehicles leaving loaded get emptier and emptier as their route unfolds from delivery point to delivery point. This inefficiency has a huge impact on the environment and on the profitability of both manufacturer and carrier. Products are mostly stored in networks of warehouses and distribution centres and are not available: i) quickly, ii) with low transportation costs, and iii) where needed. Products commonly travel thousands of kilometres, which can be avoided by making or assembling them much nearer to their point of use (Montreuil, 2011a; tinyurl.com/83guvh5).

Furthermore, critical variables such as costs, delays, and quality have a major influence on the design of value chains, thus acting as major constraints on business models. These constraints have a bearing on supply and how that supply is created. For example, e-commerce websites and mass customization efforts are hindered in part by delivery costs as well as by the sometimes-prohibitive coordination efforts required to match production and the appropriate distribution channels.

In order to address all these issues, there is no choice but to change the fundamentals of logistics and supply chain management. The Physical Internet $(\pi)$ is a paradigm-breaking vision - inspired by the Digital Internet - that enables organizations to move and deploy physical products seamlessly though logistical networks like data packets move through heterogeneous equipment respecting the TCP/IP protocol of the Digital Internet in a way that is transparent to the user (Montreuil, 2011a; tinyurl.com/83guvh5).

The first section of this article describes key concepts of the Physical Internet. The second section proposes a framework of business model innovation enabled by the Physical Internet. The third section explores how the Physical Internet enables business models that are transient, yet robust. 


\section{The Physical Internet and Business Model Innovation}

Benoit Montreuil, Jean-François Rougès, Yan Cimon, and Diane Poulin

\section{The Physical Internet}

The Physical Internet constitutes a path-breaking solution to the inefficiencies of traditional proprietary models (Montreuil, 2011a; tinyurl.com/83guvh5). It represents an open, global, interconnected, and sustainable logistics system. This system is based on standard containers that are easily transported through various transport means (e.g., planes, trucks, and also private cars). The containers move though distributed, multimodal transportation networks in which transit sites aggregate containers from diverse origins to optimize the loading on the next segments. Open warehouses and open logistics facilities are part of the network, enabling a global Logistics Web. As such, in order to clearly differentiate it from classical logistical activities, it is said to be $\pi$-enabled as the Physical Internet goes beyond the development of agile networks known in the literature (Montreuil et al., 2000: tinyurl.com/6s7rwaw; Lee, 2004: tiny url.com/8x4oqd3).

The Physical Internet spans four layers (Montreuil, 2011a: tinyurl.com/83guvh5; 2011b: physicalinternetinitiative .org), as shown in Figure 1. At the first layer lies a Realization Web for open distributed conception and manu-
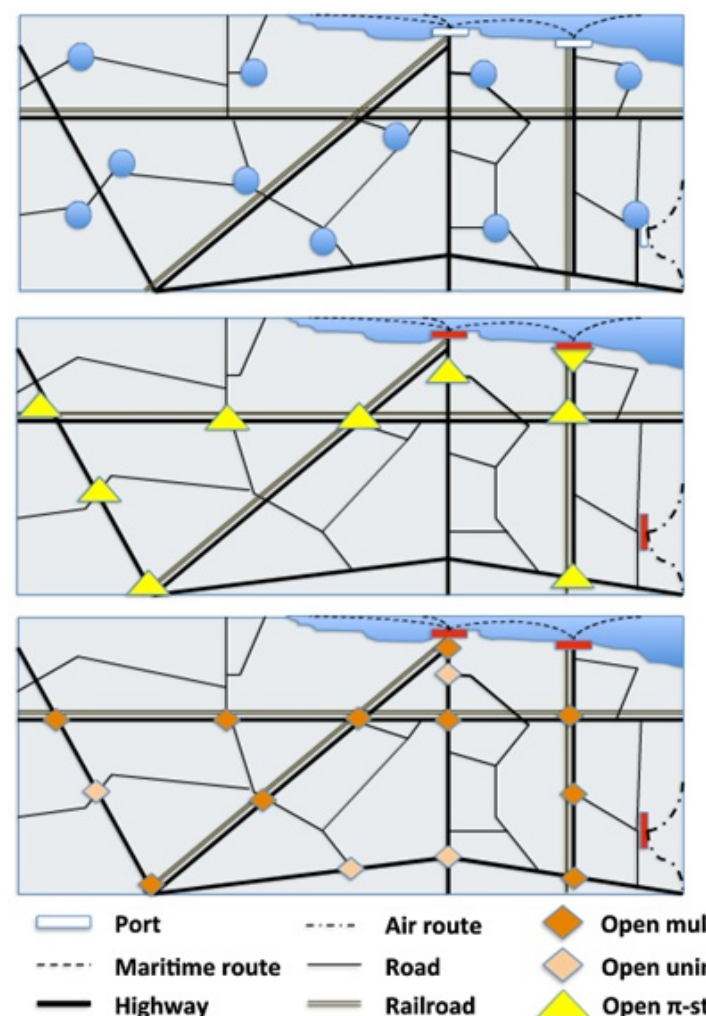

Open $\pi$-store \& $\pi$-distributor zone facturing of objects. At the second layer is embedded a Distribution Web that serves to openly deploy encapsulated objects across territories and markets. The third layer involves seamlessly moving encapsulated objects though an open multimodal Mobility Web. Through these layered webs, the Physical-Internet-enabled Logistics Web can infinitely (re)combine, thus creating yet-unheard-of possibilities for business model innovation. To put the Physical Internet into a current, real-life context, consider the UPS logistics network including trucks, planes, hubs and factories - as a closed, proprietary form of the Physical Internet.

\section{A Key Driver of Business Model Innovation}

Business models can be thought of as the way a company creates value in a competitive landscape (Magretta, 2002: tinyurl.com/78knpfc; Muegge, 2012; timreview.ca/article/545) and may be dynamic as value-creation patterns shift within and between firms (Mason and Leek, 2008; tinyurl.com/79gf2ys).

The Physical Internet is a key driver of business model innovation. In rapidly evolving industries, such as optical networking at the end of the 1990s, firms acquired in-

\section{Realization Web \\ Open Production, Personalization \& Retrofit Centers \\ Distribution Web \\ Open \\ Distribution Centers \& Warehouses \\ Supply Web \\ Logistics Web}

\section{Mobility Web}

\author{
Open \\ Unimodal \& Multimodal \\ Hubs \& Transits
}

Figure 1. The four layers of the Physical Internet* 


\section{The Physical Internet and Business Model Innovation}

\section{Benoit Montreuil, Jean-François Rougès, Yan Cimon, and Diane Poulin}

novative capabilities from the market (e.g., Carpenter et al., 2003; tinyurl.com/85galnr). Value can also be created from innovations that result from efficient knowledge transfer. For Chesbrough (2007; tinyurl.com/7sne52v), open innovation is an element to be taken into account in business models. The Physical Internet provides the framework to go beyond this view by enabling business model innovation and not just business models around specific types of innovation.

Past work by Linder and Cantrell (2000; tinyurl.com/ 848uj54) identifies four types of business models innovation strategies: realization, renewal, extension, and journey. These authors go on to specify that a realization strategy is focused on maximizing returns and suggests a level of operational excellence. A renewal strategy is based on the constant evolution of products and services while remaining true to an original model. An extension strategy adds new value-creating activities within the firms' value chain. Finally, a journey strategy focuses on major overhauls and transformation of the firms' business model. Linder and Cantrell further suggest that, as a firm moves along that continuum, the changes become more transformational.

In the context of the Physical Internet, there are two important categories of firms: the $\pi$-Enablers and the $\pi$-Enabled. As depicted in Figure 2, while the former provides baseline infrastructural tools such as containers, vehicles, services, and software, the latter exploits the potential value creation induced by the Physical Internet to create value for the full range of stakeholders involved. This may be explained by the fact that value is co-created by firms that are now in a position to leverage their asymmetries, notwithstanding their respective levels of heterogeneity (Papadopoulos et al., 2008; tinyurl .com/7bzwnh2).

Figure 2 shows the relationships between $\pi$-Enabler firms and $\pi$-Enabled firms. The introduction of the Physical Internet will force firms to innovate. $\pi$-Enabler firms provide the necessary physical and material infra-

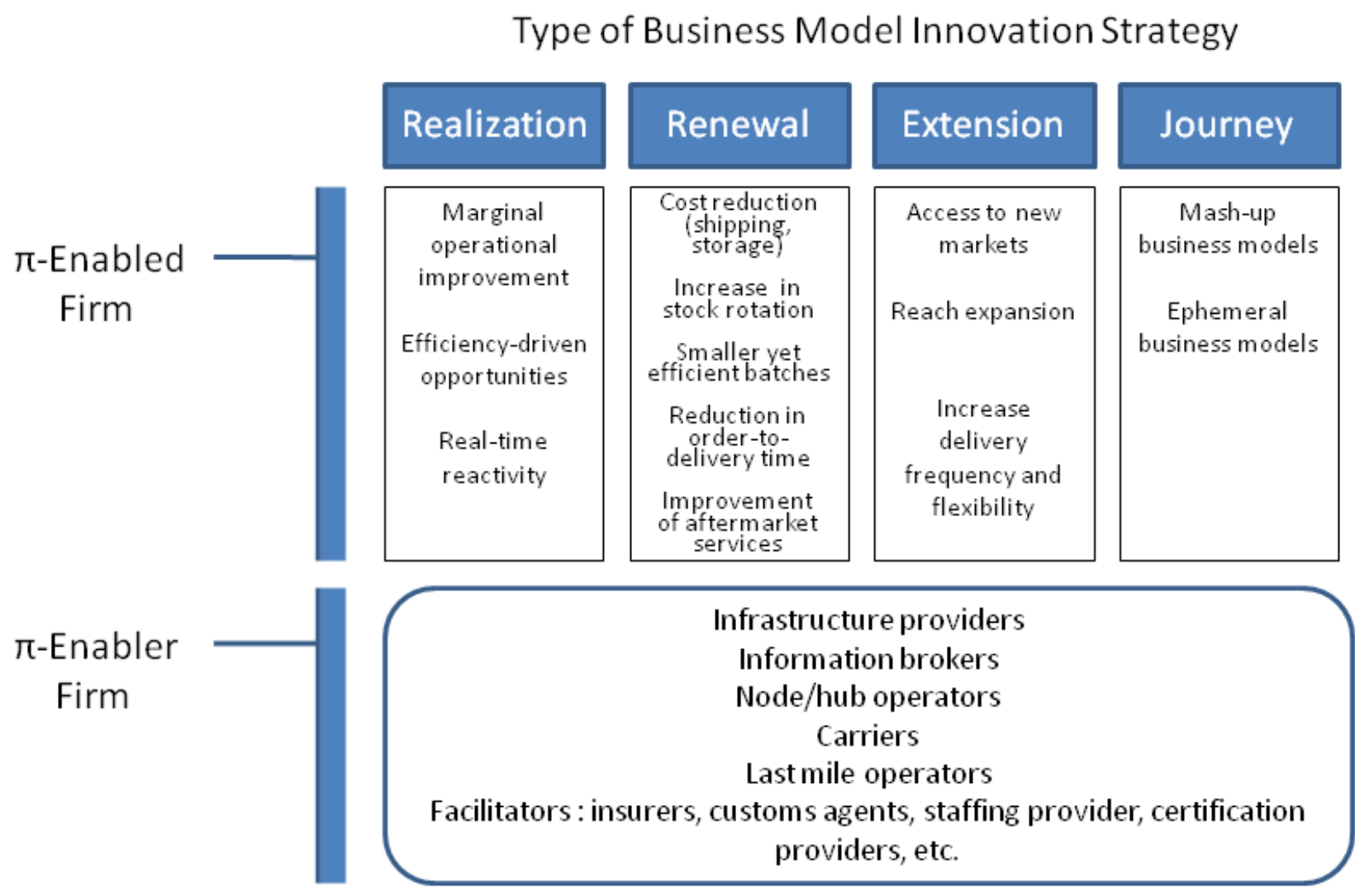

Figure 2. Implications of different types of business model innovation strategies for $\pi$-Enablers and $\pi$-Enabled firms*

*Adapted and expanded from Montreuil (2011a; tinyurl.com/83guvh5) and Linder and Cantrell (2000; tinyurl.com/848uj54) 


\title{
The Physical Internet and Business Model Innovation
}

\author{
Benoit Montreuil, Jean-François Rougès, Yan Cimon, and Diane Poulin
}

structure, including a full range of services. The standardization that this suggests for the Physical Internet to be efficient (e.g., containers, vehicles, equipment) will transform current providers.

For example, one can imagine that car manufacturers will use standardized containers both for inbound supply purposes and outbound distribution purposes, thus altering (Renewal) their business model, which is highly dependent on trucking, in North America at least. This may lead them to adopt or devise radically different logistical solutions (Extension) or even to create new bundles of products-markets-services that go beyond car manufacturing (Journey).

By the same token, infrastructure providers will be strongly impacted. The Mobility and Distribution Webs discussed earlier mean that transit centres, hubs, distribution centres, and warehouses will be flexible nodes of an elaborate and flexible network that will transform the way cargo, storage, and routing will be done. Lastmile operations are then to be better customized for rural and urban deliveries that will prove less dependent on traffic patterns and population density. This may be done using a mix of public/private means, whether proprietary or not.

In turn, customs agents, insurers, logisticians, and information systems developers will be impacted as new services will become profitable despite a change in intermediation relationships that will provide for real-time optimization. As an early example Tri-Vizor (trivizor.com) introduces itself as "the world's first supply chain orchestrator". It "proactively designs and operates horizontal partnerships and collaborative communities among shippers by bundling and synchronizing freight flows across multiple supply networks".

\section{Toward Increasingly Transient-Yet-Robust Business Models}

Business models in the realization category have one option for change: a relentless drive toward efficiency and operational excellence. Business models focused on renewal will allow firms to go beyond the constraints imposed by their value chains. Manufacturers will have the opportunity to reduce the costs of supply, storage, and shipping, to minimize order-to-delivery time, and to develop reactivity. Retailers will improve the efficiency of their logistics flows, notably increasing stock-rotation frequency and in-store product availability, which are key success factors when small, customized batches are at the core of the retailer's competitive advantage.
Those engaged in extension-driven business models will cover an ever-increasing span of products and markets in an ever-increasing economically viable manner. Manufacturers will have the opportunity to reach new markets by increasing frequency, reducing constraints related to lot size, and reducing the cost of delivery. The mass customization of products will become easier thanks to the reduction of shipping costs and with the development of a distributed network of open factories, which will enable the creation of a more flexible and adaptive value chain. For their part, retailers will have the opportunity to open stores in new markets at the periphery of existing logistics networks, in areas that are not profitable in the current context. The development of smaller, "right-sized" shops will be profitable.

On another note, journey business models will be deployed in many ways. Figure 3 depicts two such ways: mash-up models and ephemeral models. First, mashups are a bundle of many consumer trends, with the impetus to mix existing elements, such as combining many branded elements in order to create a unique product that corresponds to an individualized experience. This type of business model is currently very complex to implement as uniqueness is harder to come by and often very costly. The Logistics Web enables small batches to be made at a lower cost and closer to customers, which is ideal for fragile or highly specific orders.

Ephemeral business models are characterized by mobility and customer experiences akin to those of popup stores. This model specifically addresses the need for a customer experience that is leading edge and strong. When a business adopts this model, it provides a highly tailored consumer experience. It renders small market niches very attractive because it does not require the wide proprietary infrastructure of classical department stores.

Nowadays, many business models coexist. The Physical Internet multiplies the opportunities for tailored models that simultaneously enrich customer's experiences and drive high-value creation for businesses to thrive from. By allowing efficient, seamless, open, decentralized and distributed mobility, distribution, production, and supply in tune with point-of-sale mobility and flexibility, the Physical Internet provides numerous opportunities for enhancing existing business models and designing novel business models. It can transform unprofitable or unreachable markets and ideas into attractive business opportunities. 


\section{The Physical Internet and Business Model Innovation}

Benoit Montreuil, Jean-François Rougès, Yan Cimon, and Diane Poulin

\section{Mash-up Business Model}

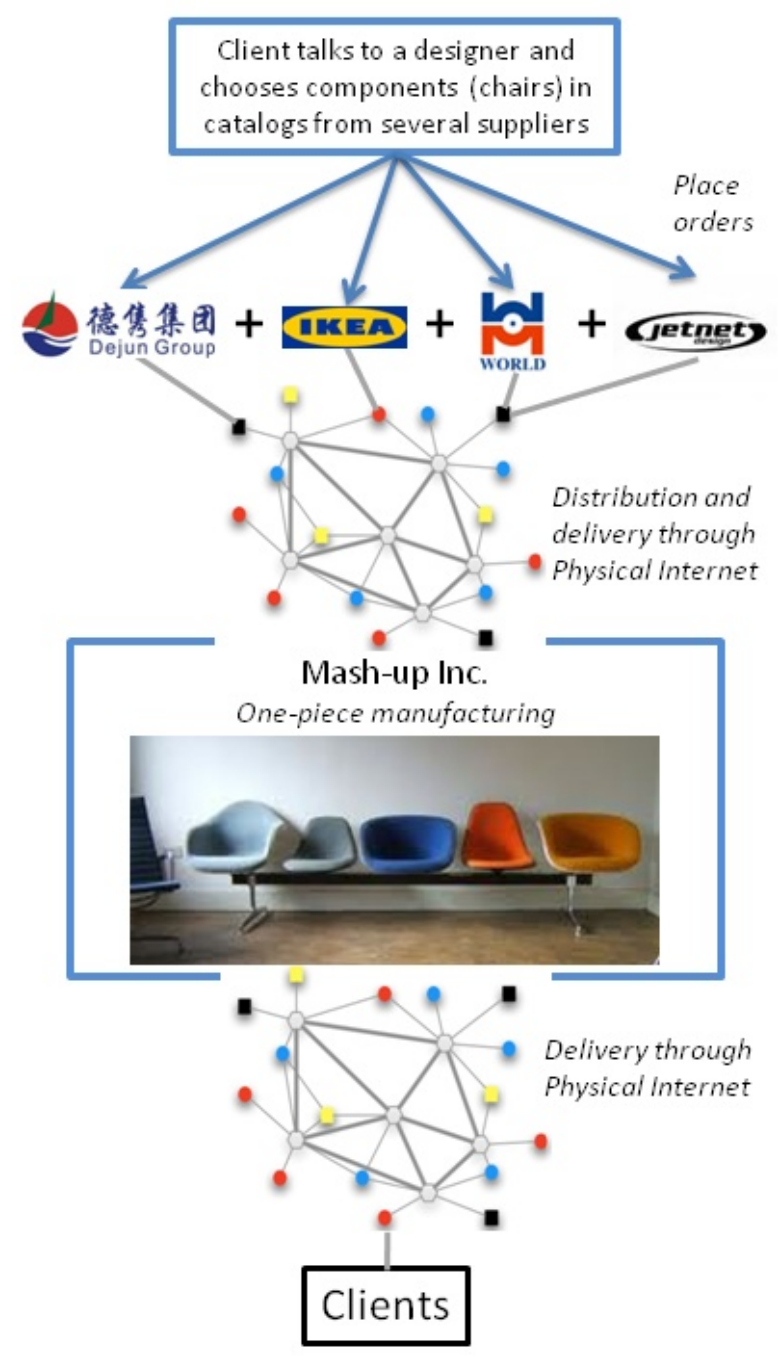

Figure 3. Mash-up and ephemeral business models

\section{Ephemeral and Mobile Business Model}

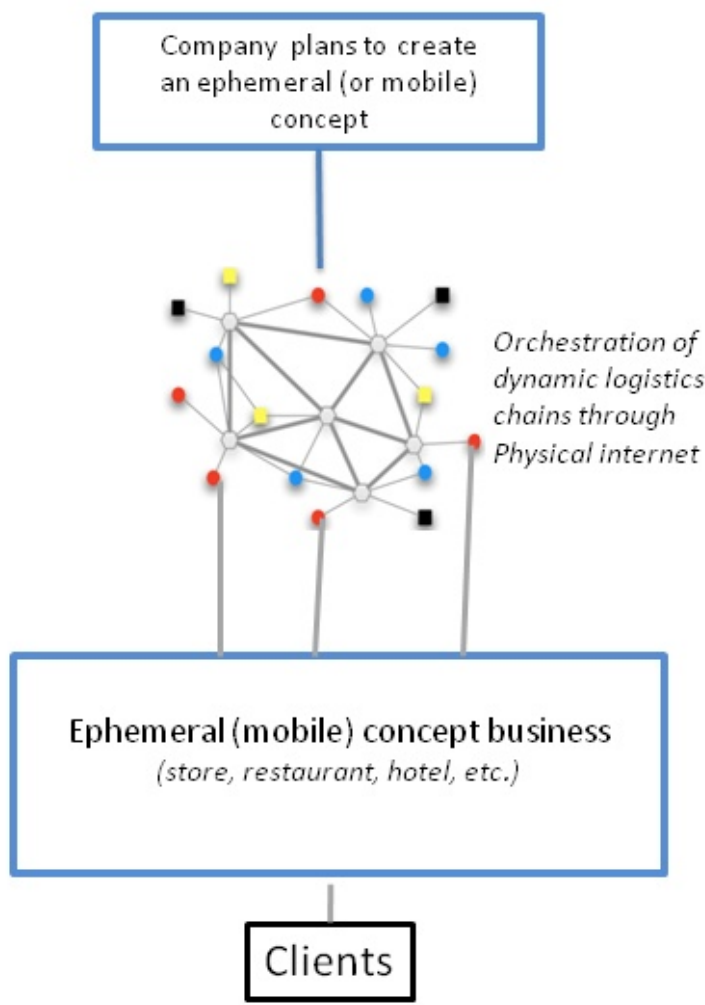




\title{
The Physical Internet and Business Model Innovation
}

\author{
Benoit Montreuil, Jean-François Rougès, Yan Cimon, and Diane Poulin
}

\section{Conclusion}

Introducing a new infrastructure such as the Physical Internet generates an intense wave of innovative change in business models. Firms are now in a position to leverage their asymmetries in order to push further value creation (Cimon, 2004; tinyurl.com/73u97f7). Electricity and the Digital Internet were game changers just as the Physical Internet will be.

Thus, the Physical Internet will instil a change of several orders of magnitude as this infrastructure and business models will continue to influence one another. We face a revolution as radical as the Internet Revolution. "Brick and Mortar Firms" will seize on the occasion to improve on a spectrum that spans from improving on current business model to radically altering them, and a vast room of opportunities is opening for "start-up" entrepreneurs that are able to invent new ways to create value through the Physical Internet.

Further research on the topic is much needed. For example, there should be research focusing on the strategic role of communications and information technology when considering the morphology of business models (Cimon et al., 2009; Proc. Int. Conf. Industrial Eng. and Sys. Man.) and its alignment with strategy (Rouges et al., 2010; tinyurl.com/84bh9k9). There is also critical need for research pushing the frontiers of current business paradigms that would be challenged by a Physical-Internet-enabled world. For example, the Physical Internet could help with the introduction of efficient and sustainable cloud manufacturing and cloud storage in the material world (e.g. Montreuil 2011a: tiny url.com/83guvh5; $\mathrm{Xu}, 2012$ : tinyurl.com/7wtonj8).

\section{About the Authors}

Benoit Montreuil, P. Eng., Ph.D. (Georgia Tech, ISYE, 1982) is Professor in the Faculty of Administration Sciences at Université Laval in Quebec City, Canada. He holds the Canada Research Chair in Enterprise Engineering. He is a board member of the CIRRELT Interuniversity Research Centre on Enterprise Networks, Logistics and Transportation. He is a member of the EDS Institute on Environment, Development and Society. He is the MHIA Board Liaison of the College Industry Council on Material Handling Education. His main research interests lie in developing concepts, methodologies and techno- logies for creating, optimizing, transforming and enabling businesses and value creation networks to thrive in a fast evolving world. He is the inventor of the Physical Internet towards efficient and sustainable interconnected logistics. He is leading the International Physical Internet Initiative. DC Velocity has named him 2011 Rainmaker-of-the-Year.

Jean-François Rougès is $\mathrm{PhD}$ Student at the Faculty of Business Administration at Université Laval (Québec City, Canada), member of the member of the CIRRELT, Interuniversity Research Centre on Enterprise Networks, Logistics and Transportation. His research focuses on strategy and business model innovation enabled by information and communication technologies. He also works as a consultant in strategic change management.

Yan Cimon, C.D., Ph.D. (HEC Montreal) is Associate Professor of Strategy at the Faculty of Business Administration at Université Laval (Quebec City, Canada). He is the Deputy Director of CIRRELT (Québec), the Interuniversity Research Center on Enterprise Networks, Logistics and Transportation. $\mathrm{He}$ is also an associate member of HEI, the Quebec Institute for Advanced International Studies. His research focuses on networks and alliances between firms. His most recent research focuses on the dynamics of Canada-US value chain integration as to better leverage the innovative power of complex North American value creation networks that are too often overlooked. A winner of many awards for the implications and impact of his work, he was also elected to Alpha Iota Delta.

Diane Poulin, Ph.D. (École Polytechnique de Paris/France) is full Professor of Strategy at the Faculty of Business Administration at Université Laval (Quebec City, Canada). She is a founder member of CIRRELT (Québec), the Interuniversity Research Center on Enterprise Networks, Logistics and Transportation. She is also a member of CeRTAE, Enterprise Architecture and Transfer Research Center, and FORAC, Research Consortium of expertise for the advancement of the forest products industry. Her research focuses on innovation and technologies, networks enterprises and alliances.

Citation: Montreuil, B., J.F. Rougès, Y. Cimon, and D.

Poulin 2012. The Physical Internet and Business Model

Innovation. Technology Innovation Management Review. June 2012: 32-37. 